\title{
Two Patients With Bepridil-Induced Interstitial Pneumonia
}

\author{
Masataka Watanabe, MD; Yoshifumi Takata, MD; Shinya Fukasawa, MD; Kunihiro Sakota, MD; \\ Tetsuya Abe, MD*; Yoshinari Goseki, MD; Yasuhiro Setoguchi, MD*; \\ Taishiro Chikamori, MD; Akira Yamashina, MD
}

\begin{abstract}
Two patients developed bepridil-induced interstitial pneumonia during treatment of arrhythmia. The first patient was a 69-year-old man who received bepridil to maintain sinus rhythm in atrial fibrillation and who developed dyspnea on the $20^{\text {th }}$ day after administration. The second patient was a 72 -year-old man who received bepridil for paroxysmal atrial fibrillation and who developed dyspnea on the $60^{\text {th }}$ day after administration. They were diagnosed with interstitial pneumonia on the basis of physical and imaging findings. The first patient was discharged after steroid pulse therapy, and the second patient after improvement of physical and imaging findings when bepridil was discontinued. Although a limited number of cases of bepridil-induced interstitial pneumonia have been reported, the disorder should be kept in mind as an important adverse reaction when breathlessness or dyspnea develops during administration of the drug. (Circ J 2009; 73: 1352-1355)
\end{abstract}

Key Words: Atrial fibrillation; Bepridil; Interstitial pneumonia

B epridil, a drug that inhibits the $\mathrm{Na}^{+}, \mathrm{K}^{+}$, and $\mathrm{Ca}^{2+}$ channels in cardiomyocytes, has electrophysiological properties of Vaughan Williams class I, III, and IV antiarrhythmic drugs. It exerts its antiarrhythmic effect by reducing the maximum depolarization rate of atrial muscle, the atrioventricular node, ventricular muscle, and others. Recently, bepridil was found to have a blocking effect on IKs, a $\mathrm{K}^{+}$channel subtype, similar to amiodarone, and to exhibit an antifibrillatory effect by increasing refractoriness during tachycardia! Furthermore, bepridil has been reported as effective for the pharmacological defibrillation of atrial fibrillation that has persisted for 3 or more months, and in the maintenance of sinus rhythm after electrical defibrillation, ${ }^{2,3}$ Known adverse reactions for bepridil are severe conduction disturbance, marked sinus bradycardia, and increased QT interval; however, beperidil-induced interstitial pneumonia is very rare, and its incidence is considered unknown.

\section{Case Reports}

\section{Patient 1}

A 69-year-old man presented to hospital with the chief complaint of exertional dyspnea. In June 2007, pilsicainide $150 \mathrm{mg} /$ day and bepridil $100 \mathrm{mg} /$ day were administered for paroxysmal atrial fibrillation; however, sinus rhythm was not maintained. An increased dose of bepridil to $200 \mathrm{mg} /$ day succeeded in maintaining sinus rhythm. The patient developed dyspnea at approximately 2 months after the onset of the medication and underwent medical examination for the deteriorated symptoms as an outpatient. At the time of his

(Received March 10, 2008; revised manuscript received July 14, 2008; accepted July 24, 2008; released online December 27, 2008)

Department of Cardiology, *Department of Respiratory Medicine, Tokyo Medical University, Tokyo, Japan

Mailing address: Masataka Watanabe, MD, Department of Cardiology, Tokyo Medical University, 6-7-1 Nishi-Shinjuku, Shinjuku-ku, Tokyo 160-0023, Japan. E-mail: watamasa@tokyo-med.ac.jp All rights are reserved to the Japanese Circulation Society. For permissions, please e-mail: cj@j-circ.or.jp visit to the hospital, he was in respiratory failure (HughJones class IV) and fine crackles were audible in the right and left lung fields. Hematology revealed abnormally high concentrations of white blood cells (WBC: 10,900/ $\mu$ l), Creactive protein (CRP: $14.3 \mathrm{mg} / \mathrm{dl})$, and KL-6 $(1,230)$. Furthermore, chest X-rays indicated diffuse bilateral infiltrates located predominantly in the peripheral lung fields. Computed tomography of the chest, which was conducted simultaneously, revealed diffuse infiltrates located predominantly on the posterior side of the lower lung fields (Figure 1). Therefore, the patient was diagnosed with bepridilinduced interstitial pneumonia and admitted to the hospital immediately. $\mathrm{AaDO}_{2}$ increased to 118 torr after admission; favorable oxygenation $\left(\mathrm{PaO}_{2}, 94\right.$ torr; $\left.\mathrm{O}_{2}, 2 \mathrm{~L} / \mathrm{min}\right)$ led to discontinuation of bepridil and follow-up oxygen administration. On the $3^{\text {rd }}$ day of admission, $\mathrm{AaDO}_{2}$ further increased to 273 torr and his respiratory status deteriorated. Therefore, we started steroid pulse therapy by administering $1,000 \mathrm{mg}$ of prednisolone for 3 days, and gradually reducing the dose. The patient responded well to the therapy, and the diffuse bilateral infiltrates improved. On the $30^{\text {th }}$ day of admission, his respiratory failure had improved to HughJones class I and he was discharged walking by himself (Figure 2).

\section{Patient 2}

A 72-year-old man presented to hospital with the chief complaint of exertional dyspnea. In July 2003, the patient was followed up with pilsicainide administration for paroxysmal atrial fibrillation on an as-needed basis. Paroxysms had occurred frequently since 2006, and heart failure tended to develop. The drug was changed to bepridil $100 \mathrm{mg} /$ day to maintain sinus rhythm. However, the patient had a medical examination as an outpatient because of exertional dyspnea while walking and deterioration of respiratory function since about the $40^{\text {th }}$ day after beginning the medication. At the time of his visit to the hospital, he was in respiratory failure (Hugh-Jones class III) and fine crackles were audible in the right and left lung fields. Hematology revealed high concentrations of WBC $(9,800 / \mu 1)$, CRP 


\section{A}
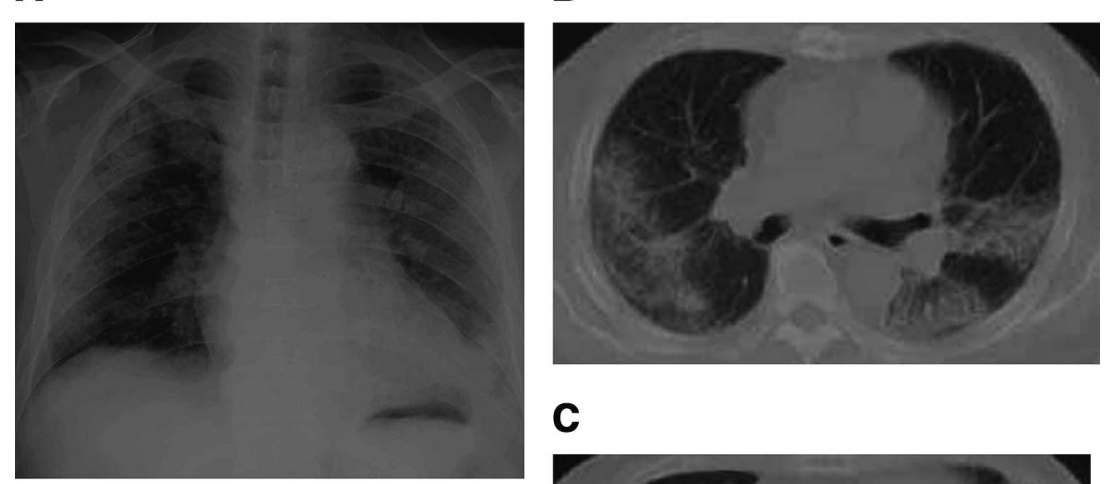

C
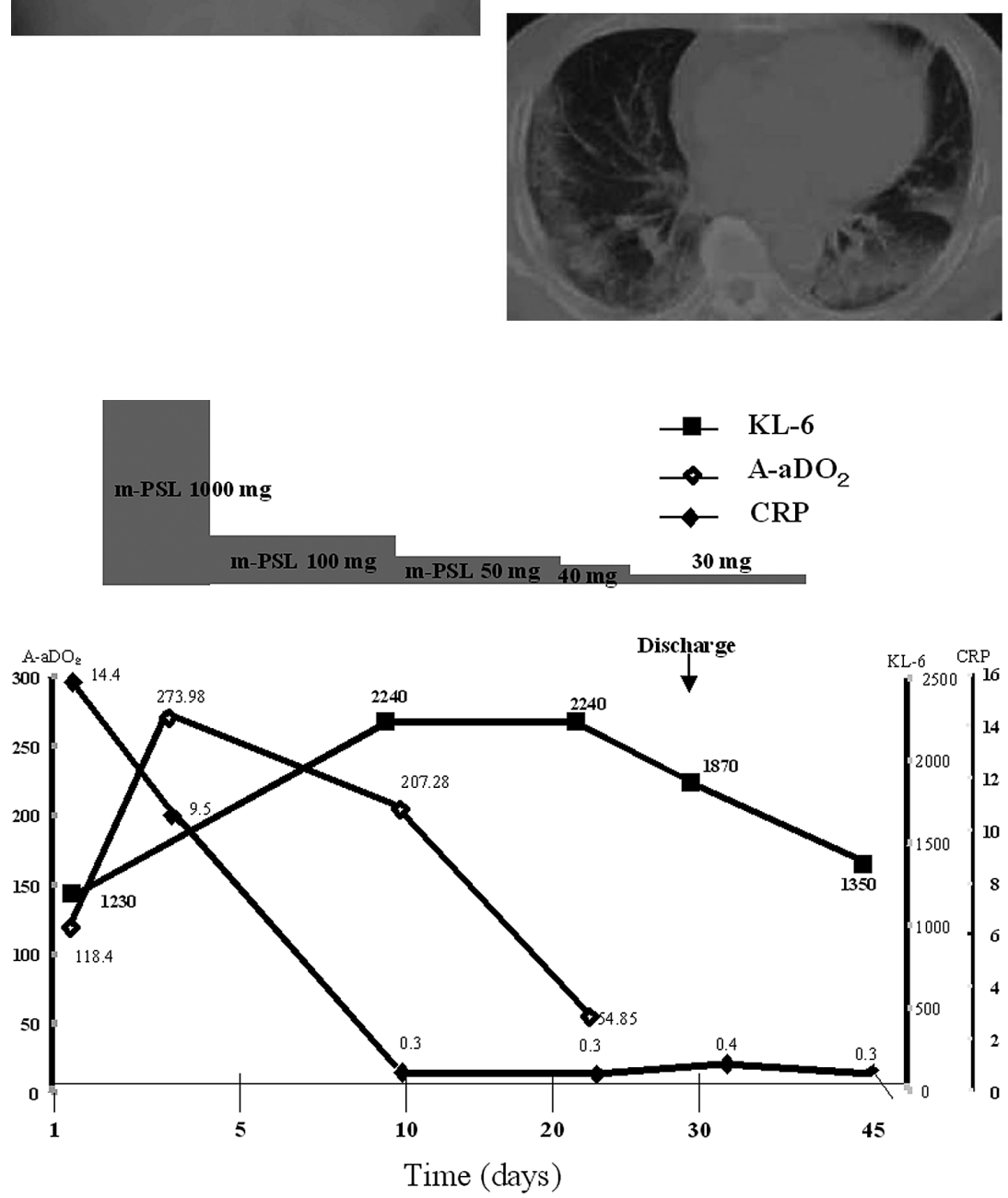

Figure 1. Patient 1. (A) Chest X-ray showing diffuse bilateral infiltrates predominantly in the peripheral lung fields. $(\mathbf{B}, \mathbf{C})$ Plain CT scans of the chest show diffuse bilateral infiltrates predominantly in the peripheral lung fields, the so-called "negative butterfly shadows", which resemble the imaging findings of eosinophilic pneumonia.
Figure 2. Patient 1: clinical course. $\mathrm{AaDO}_{2}$ increased after admission to hospital, and steroid pulse therapy was started from the $3^{\text {rd }}$ day of disease because of deteriorated oxygenation. Oxygenation, $\mathrm{AaDO}_{2}$, and $\mathrm{C}$-reactive protein (CRP) improved rapidly after the onset of steroid pulse therapy. However, blood KL-6 concentrations also increased and were maintained at a high level after symptoms improved. On the $30^{\text {th }}$ day of disease, the patient's clinical symptoms improved and he was discharged.
(0.3 mg/dl), and KL-6 (3,960). Chest X-rays showed diffuse infiltrates in the right lower lung field. Computed tomography of the chest, which was conducted simultaneously, revealed intense diffuse infiltrates on the posterior side of the inferior lung fields (Figure 3). Therefore, the patient was diagnosed with bepridil-induced interstitial pneumonia and was admitted to hospital immediately. After admission, the patient did not present dyspnea at rest, so bepridil was discontinued, and the patient was followed up. Respiratory status improved rapidly after discontinuation of bepridil, and the diffuse infiltrates on chest X-rays and CT scans improved rapidly. On the $20^{\text {th }}$ day of admission, respiratory failure had improved to Hugh-Jones class I and the patient was discharged.

\section{Discussion}

We describe the development of bepridil-induced interstitial pneumonia in 2 patients who were on treatment for arrhythmia. Both patients were diagnosed with the disorder on the basis of clinical course, laboratory findings, and imaging findings. Bepridil was administered to these patients in whom sinus rhythm could not be maintained with other antiarrhythmic drugs. We compare our 2 patients with 3 patients with beperidil-induced interstitial pneumonia who have been reported in the literature ${ }^{4-6}$ and for whom the objective of bepridil administration was known (Table). All the patients were elderly men, and none of them had a definite previous history of interstitial pneumo- 
A

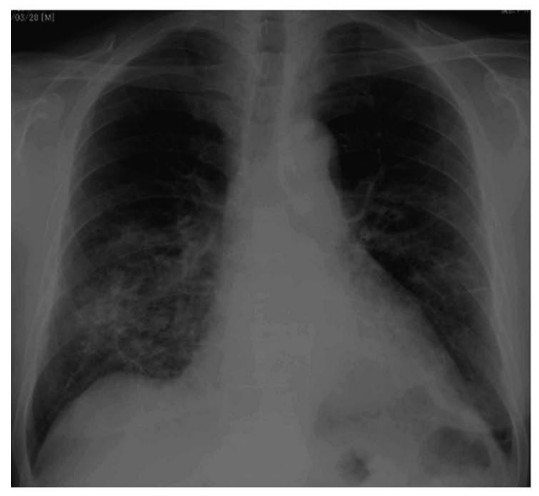

B

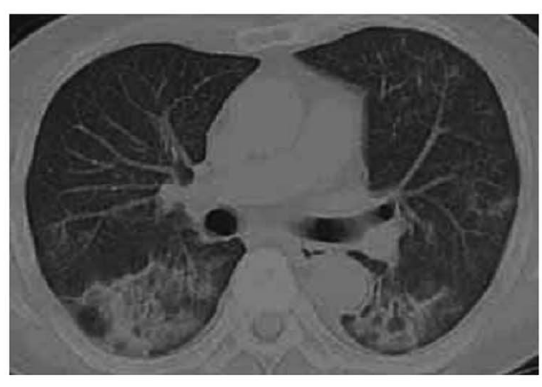

C

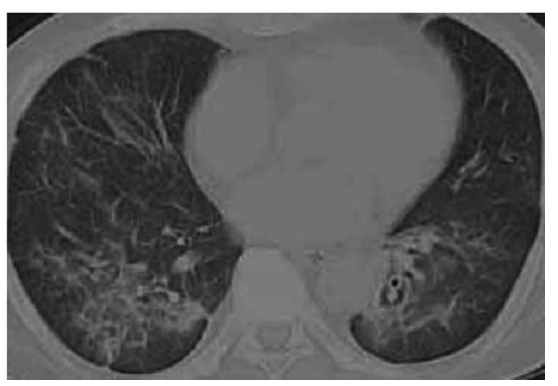

Figure 3. Patient 2. (A) Chest X-ray shows diffuse small granular infiltrates and a "groundglass" appearance, predominantly in the right and left lower lung fields. (B,C) Plain CT scans of the chest depicting diffuse, centrilobular, small granular infiltrates, as well as increased densities of the lung fields, predominantly in the right and left lower lung fields, resembling the imaging findings of hypersensitivity pneumonitis.

Table. Demographic Characteristics of Reported Patients With Bepridil-Induced IP

\begin{tabular}{|c|c|c|c|c|c|c|c|c|}
\hline & Gender & $\begin{array}{c}\text { Age } \\
\text { (years) }\end{array}$ & History of IP & Smoking habit & Arrhythmia & $\begin{array}{l}\text { Bepridil dose } \\
\text { (mg/day) }\end{array}$ & $\begin{array}{l}\text { Time interval* } \\
\text { (days) }\end{array}$ & $\begin{array}{c}\text { Steroid pulse } \\
\text { therapy }\end{array}$ \\
\hline Vasilomanolakis \& Goldberg 5 & M & 72 & Unknown & Unknown & $\mathrm{AF}$ & 400 & 21 & Yes \\
\hline Gaku et $\mathrm{al}^{6}$ & M & 65 & Unknown & Unknown & $\mathrm{AF}$ & 150 & 14 & No \\
\hline Okubo et $\mathrm{al}^{4}$ & M & 66 & Negative & Negative & $\mathrm{AF}$ & 200 & 30 & No \\
\hline Patient 1 & M & 69 & Negative & Negative & $\mathrm{AF}$ & 200 & 60 & Yes \\
\hline Patient 2 & M & 72 & Negative & Negative & $\mathrm{AF}$ & 200 & 40 & No \\
\hline
\end{tabular}

*Time interval between the initiation of bepridil treatment and the development of symptoms suspicious of IP

$\mathrm{IP}$, interstitial pneumonia; AF, atrial fibrillation.

nia. The mean duration between onset of administration of bepridil and the development of dyspnea was 33 days. Regarding the doses of bepridil, the patient reported by Vasilomanolakis et al received a high dose of bepridil $400 \mathrm{mg} /$ day, whereas the doses for the 4 patients in Japan were as low as 150-200 mg/day. In all cases bepridil was used to maintain sinus rhythm in atrial fibrillation.

The number of drugs reported to induce interstitial pneumonia is as many as 200? Furthermore, drug-induced interstitial pneumonia accounts for as high as $6.7 \%$ of the adverse reactions are listed in Drugs in Japan at April 2004, and different types of drugs have been shown to possibly induce the disorder. Therefore, it can be difficult to identify the causative drug and in many patients the diagnosis is often made on the basis of the clinical course of the disorder, as was the case for the 2 patients presented here. Drug identification by drug lymphocyte stimulation test is predominantly considered an adjunct to clinical diagnosis,, 9

In the field of cardiology, amiodarone is well known for inducing interstitial pneumonia. There are many diagnostic criteria for the disorder because, although rare, pulmonary complications can be fatal. Checking the present 2 patients against the criteria proposed by Martin et al ${ }^{10}$ led us to the diagnosis of drug-induced interstitial pneumonia, and the 3 patients in the literature also fulfilled these criteria. Therefore, the clinical diagnostic criteria for amiodarone-induced pneumotoxicity proposed by Martin et al are also useful for the diagnosis of bepridil-induced interstitial pneumonia. A recent study of sporadic interstitial pneumonia in Japan ${ }^{11}$ revealed the involvement of genetic polymorphism of a specific gene (exon 5) for surfactant protein $\mathrm{C}$, a type of alveolar surfactant protein, thus suggesting the possible involvement of a genetic predisposition in the pathogenesis of interstitial pneumonia. Therefore, we presume that a similar mechanism is also present for drug (bepridil)induced interstitial pneumonia and consider that future research on susceptibility genes will be required for druginduced interstitial pneumonia in the field of cardiology.

In general terms, drug-induced interstitial pneumonia is known to show many imaging patterns. In fact, these 2 patients showed different imaging patterns and had few of the characteristic findings, as did the patients in the literature. This indicates the difficulty in detecting drug-induced interstitial pneumonia from the features of typical imaging findings. Similar imaging findings have been reported for amiodarone-induced interstitial pneumonia, of which there are many cases. In consideration of pharmacokinetics, however, bepridil has a short blood half-life in contrast to the long blood half-life of amiodarone, a liposoluble drug. Therefore, we consider that early detection of bepridilinduced interstitial pneumonia and then discontinuation of the drug are of great clinical value. 
At present, commercially available bepridil is indicated in Japan only for angina pectoris and ventricular tachyarrhythmia. In fact, however, bepridil is used to maintain sinus rhythm in atrial fibrillation in many patients. This offlabel use of bepridil may explain the limited number of reported cases of bepridil-induced interstitial pneumonia.

In conclusion, interstitial pneumonia occasionally may be fatal, so it is important to make a quick differential diagnosis from heart failure and to actively suspect beperidil when observing dyspnea or physical findings during its administration.

\section{Acknowledgment}

I received Young Investigator's Award on The 206th Scientific Meeting of Japanese Circulation Society division of Kanto-koshinnetu district meeting for this report.

\section{References}

1. Task Force of the Working Group on Arrhythmias of the European Society of Cardiology. The Sicilian gambit: A new approach to the classification of antiarrhythmic drugs based on their actions on arrhythmogenic mechanisms. Circulation 1991; 84: 1831-1851.

2. Fujiki A, Tsuneda T, Sakabe M, Nakagawa K, Mizumaki K, Hirai T, et al. Maintenance of sinus rhythm and recovery of atrial mechanical function after cardioversion with bepridil or in combination with aprindine in long-lasting persistent atrial fibrillation. Circ J 2004; 68: $834-839$.

3. Nakazato Y, Yasuda M, Sasaki A, Iida Y, Kawano Y, Nakazato K, et al. Conversion and maintenance of sinus rhythm by bepridil in patients with persistent atrial fibrillation. Circ J 2005; 69: 44-48.

4. Okubo F, Ando M, Ashihara Y, Okubo T, Nishitake T, Ito T, et al. A case of drug-induced pneumonitis due to bepridil. J Jpn Respir Soc 2006; 44: 17-21 (in Japanese with English abstract).

5. Vasilomanolakis EC, Goldberg NM. Bepridil-induced pulmonary fibrosis. Am Heart J 1993; 126: 1016-1017.

6. Gaku S, Naoshi K, Teruhiko A. A case of bepridil induced interstitial pneumonitis. Heart 2003; 89: 1415.

7. Foucher P, Biour M, Blayac JP, Godard P, Sgro C, Kuhn M, et al. Drugs that may injure the respiratory system. Eur Respir J 1997; 10: 265-279.

8. Camus P. Respiratory disease induced by drugs. Eur Respir J 1997; 10: $260-264$.

9. Akoun GM, Cadranel JL, Milleron BJ, D'Ortho MP, Mayaud CM. Bronchoalveolar lavage cell data in 19 patients with drug-associated pneumonitis (except amiodarone). Chest 1991; 99: 98-104 [published erratum appears in Chest 1991; 99: 1556].

10. Martin WJ 2nd, Rosenow EC 3rd. Amiodarone pulmonary toxicity: Recognition and pathogenesis (Part I). Chest 1988; 93: 1067-1075.

11. Setoguchi Y, Ikeda T, Fukuchi Y. Clinical features and genetic analysis of surfactant protein $\mathrm{C}$ in adult-onset familial interstitial pneumonia. Respirology 2006; 11: S41-S45. 